\title{
Environmental-Friendliness in the Manufacturing Field
}

\author{
Ikuo Tanabe \\ Nagaoka University of Technology, Department of Mechanical Engineering \\ 1603-1 Kamitomioka, Nagaoka, Niigata, Japan 940-2188 \\ tanabe@mech.nagaokaut.ac.jp
}

\begin{abstract}
In the 21st century, as the importance to manufacture products with environmental-consciousness has been highlighted, manufacturers face a constant challenge to conserve energy, resources and reduce polluting waste. Moreover, in the case of the manufacturing field, large quantities of machine tool lubricating oil, cutting oil, coolant and electricity are used to achieve a smooth drive, precision machining and forced cooling. This represents a significant environmental issue as environmentally-friendly decisions in the technology design, development and production stages are rarely taken. The current research attempted to contribute to the alleviation of the environmental impact of manufacturing. Here, calculation models for a simple environmental impact check and the "Double-ECO model" for technology development were proposed. The proposed methods were then applied and evaluated in a machine tool case that used strong alkaline water mist for forced cooling during machining. It was concluded that; (1) Strong alkaline water mist forced cooling method had a significant cooling performance over the machining-generated heat. (2) the mist was eco-friendly, (3) the calculation models and the Double-ECO model technology can contribute to improve environmental-friendliness.
\end{abstract}

Keywords: Forced Cooling, Machine Tool, Strong Alkaline Water, Eco-Friendly, Double-ECO Model.

(C) Copyright 2018 Authors - This is an Open Access article published under the Creative Commons Attribution License terms (http://creativecommons.org/licenses/by/3.0). Unrestricted use, distribution, and reproduction in any medium are permitted, provided the original work is properly cited.

\section{Introduction}

In the 21st century, the importance to manufacture products in an environmentally-conscious way has been highlighted [1]. In this regard, manufacturers face a constant challenge to conserve energy, resources and reduce polluting waste. Nowadays, there are many researches related to the environmental impact of human activity, as well as countermeasures to reduce it; however, these are still insufficient [2], [3]. Particularly, in the field of manufacturing, most machine tools highly depend on cutting and cooling oils to achieve high accuracy. This represents a large environmental problem, since in most cases the cutting and cooling oils are misused, introduced into the environment and generate undesired pollution [4]. Consequently, the importance of developing new manufacturing ideas that take into account parameters such as high accuracy, high quality and a low environmental impact had been underlined. Hence, manufacturers will be in the need of daring plans, unique ideas and new technologies [5]. Therefore, even though the driving concept of this research was "Ecology", it also included concepts related to mechanical performance such as high precision machining and concepts related to cost management; such as, suitable cost of a machine tool, low running cost and low maintenance fee were included. Along this concepts, the advances on production engineering technology were also considered. For instance, machine tool thermal deformation countermeasures were attempted in order to achieve high accuracy and quality but it was at the expense of using costly equipment and a large quantity of electrical energy that were not enough to satisfy quality parameters [6]. To address this, environmental impact calculations was proposed. Additionally, the "Double-ECO model" was also proposed in order to environmental-friendliness. This model has been previously explored as a method that reconciles "Economy" and "Ecology" during the technology development process [7]. In this paper, both environmental-friendliness improving methods were applied on a milling machine that utilizes strong 
alkaline water mist to achieve a forced cooling during machining.

\section{Environmental-Friendliness Calculation Models and the Double-ECO Model}

A model to calculate the environmental impact in the manufacturing field was devised based on the Lifecycle Assessment (LCA). Currently, LCA is one of the major methodologies to calculate the environmental impact of a technology throughout its entire lifespan [8]. However, as the total lifecycle assessment sometimes is rather extensive, manufacturers that have considerable time constraints often neglect LCA considerations. Thus, the current research only considers exhaust carbon dioxide $\left(\mathrm{CO}_{2}\right)$ due to electricity and oil consumptions using two calculation models in the form of a simple LCA. The amount of exhaust $\mathrm{CO}_{2}$ due to electricity consumption was calculated through a relationship between the electricity consumption per hour and $\mathrm{CO} 2$ emissions.

The amount of exhaust $\mathrm{CO}_{2}(E C)$ due to electricity consumption $E C_{E}\left(\mathrm{~kg}-\mathrm{CO}_{2}\right)$ was calculated as follows.

$E C_{E}=0.468 \times W_{E}$

Where, 0.468 is a reference conversion value for $\mathrm{kg}$ $\mathrm{CO}_{2} / \mathrm{kWh}$ and $W_{E}$ is the amount of used electricity (kWh) [9]. The electricity considered was the electricity used by the equipment at all working times.

The amount of exhaust $\mathrm{CO}_{2}(E C)$ due to oil consumption $E C_{o}\left(\mathrm{~kg}-\mathrm{CO}_{2}\right)$ was calculated as follows.

$E C_{o}=(44 \div 12) \times D O \times E H E \times C E$

Where, $D O$ is the disposed oil $(\mathrm{k} \ell), E H E$ is the emitted heat energy (40.2 GJ / k $\ell$ ) and $C E$ is the amount of carbon emission (19.22 t-C / TJ) [9].

It was thought that the two calculation models should be used for a simple environmental-friendliness check run during the technology design and development stages. In addition, the Double-ECO model technology was also proposed for promoting environmental-friendliness. The general idea for the Double-ECO model is explained through the following flowchart shown in Fig. 1. Conventional environmentally-friendly technology development stages have environmental protection as first purpose, while their second purpose is cost-profit. Due to this order of priorities, given the different national laws and policies, such technologies suffered a diminished environemntal-friendliness due to cost.

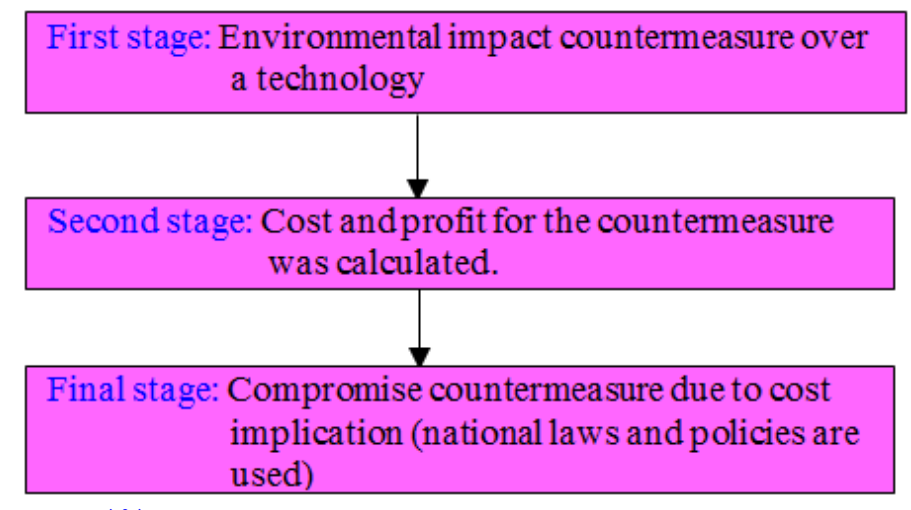

※ Final stage differs largely from the first due to compromised countermeasures

(a) Conventional environmentally-friendly technology

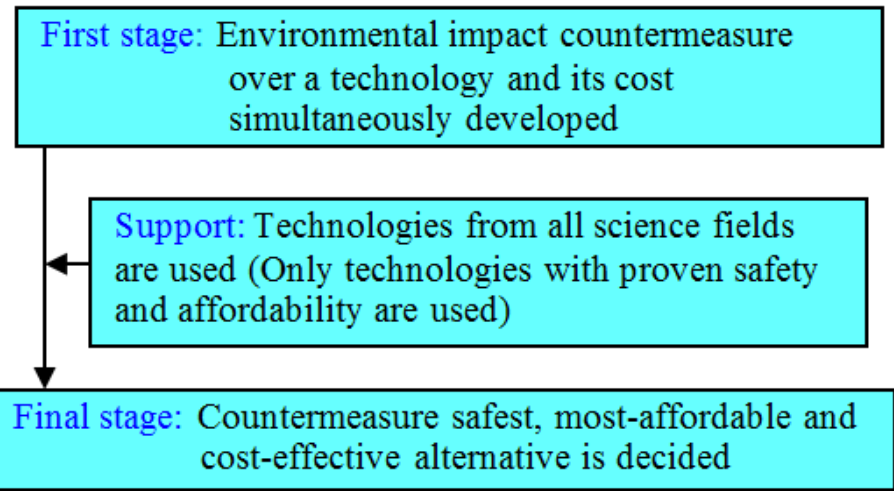

※Final stage do not differ from the first.

(b) Double-ECO model generated technology

Figure 1. Explanation regarding the general idea of the Double-ECO model technologies.

Here, the first purpose would most likely be neglected because of the high cost that they represent. Thus, environmentally-friendly technologies are advancing at a slow pace. In contrast, the "Double-ECO model" technologies prioritize simultaneously environment protection and cost-profit considerations so that no compromises are made at any time. Although it is very difficult to achieve this, recent environmentally-friendly technologies had made remarkable progress. Subsequently, the model proposed solves the technical problems with the incorporation of technology alternatives as 
countermeasures over a defined case, these countermeasures are selected from all the science fields available so that in the end the safest, most-affordable and cost-effective alternatives can be selected. At this point, the largest profit that is feasible is guaranteed so the countermeasure is not compromised.

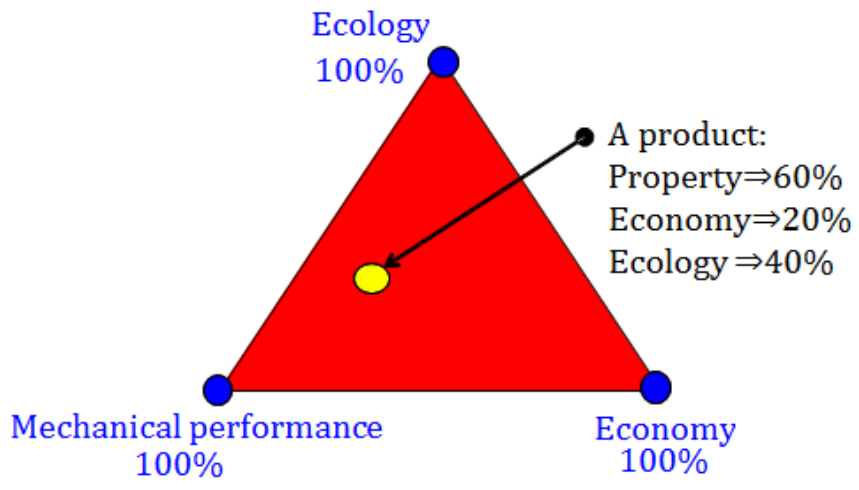

(a) Current technology

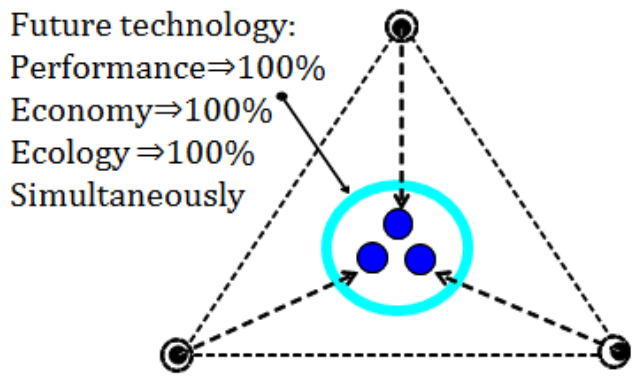

(b) Future technology using the

Double-ECO model

Figure 2. Depiction of performance evaluation of future technologies based on the Double-ECO model.

In this regard, the Double-ECO model technologies would demand an extensive knowledge of the science and economics fields for a successful development. A depiction of an evaluation platform that includes cost, mechanical performance and ecology as parameters, for future technologies using the DoubleECO model is shown in Fig. 2. Currently, most products are manufactured either on the mechanical performance and ecology or the mechanical performance and economy edges of the evaluation triangle (i.e. " $A$ " product is on the yellow point which has an ecology performance of $40 \%$, mechanical performance of $60 \%$ and an economy of $40 \%$ ). It can be observed that ecology, mechanical performance and economy often clash in the manufacturing field.

However, in the near future, through the DoubleECO model products would optimally be able to reach $100 \%$ performances on all parameters. At that stage, all manufactures would willingly become environmentallyfriendly. Here, it is necessary to consider that a definition of said parameters is necessary (i.e. what is an environment-friendliness of $0 \%$ or $100 \%$ ) which can be done through polling and statistics-driven weighting of certain parameters such as energy consumption, resulting emissions, toxicity of by-products, risk potential, etc. This particular weighting method has been explored in depth by the BASF Eco-Efficiency Analysis Methodology [10]. Moreover, a definition of the parameters that offers independence from direct weighting that relies on subjective methods (i.e. polling) would certainly be material for further research.

\section{Evaluating the Environmental-Friendliness Calculation Models and the Double-ECO Model through an Experimental Case}

The two calculation models for checking environmental-friendliness and the Double-ECO model were evaluated in this chapter. Computer numerical control (CNC) milling was performed inside a vessel with strong alkaline water mist in order to investigate the effect of water evaporation in strong alkaline water.

\subsection{Corrosion Resistance of Materials in Strong Alkaline Water}

The strong alkaline water with $\mathrm{pH}$ value above 12.5 has high interfacial permeability, dissolving, emulsification, and separation properties. For these properties, it is well suited for washing, sterilization, corrosion prevention. Moreover, when strong alkaline water is kept for a long time in the air, it loses its alkaline property and becomes normal water ( $\mathrm{pH}$ 7.0). This remarkable fact has turned alkaline water into a cleaning agent with a diminished environmental impact. In this section, the reactions of the various materials in strong alkaline water are tested. The specification of the device for making alkaline water is shown in Table 1. In the corrosion engineering field, a logarithmic value of metal ion concentration lesser than (-6) means a material does not corrode at equilibrium state; here, according to the corrosion characteristic of strong alkaline water, steel could not corrode in alkaline water with pH above 10 [11]. Similarly, Nickel based alloys 
shows no chemical reaction in the $\mathrm{pH}$ range 8.5 13.0.

Titanium alloys also shows no effect under a pH of 13.0.

Table 1. Specification of the system for making strong alkaline water and safety of strong alkaline water.

\begin{tabular}{|c|c|c|c|c|}
\hline Generation Method & Closed generation type & \multicolumn{2}{|c|}{ Assistant material } & Potassium carbonate \\
\hline Value of $\mathrm{pH}$ & pH 12.5 & \multirow{4}{*}{$\begin{array}{l}\text { Safety } \\
\text { of } \\
\text { health }\end{array}$} & Smell & Nothing \\
\hline Quantity of generation & $10 \ell / \mathrm{h}$ & & Touch & $\Delta$ Wear gloves \& glasses \\
\hline Voltage \& Power & $100 \mathrm{~V} \& 300 \mathrm{~W}$ & & Inhale & Wear mask \\
\hline Size & $495 \mathrm{~W} \times 430 \mathrm{D} \times 1100 \mathrm{H}$ & & Drink & $x$ \\
\hline
\end{tabular}

$\circ$ :No problem $\Delta$ :Avoid $\times$ :Prohibition

Table 2. The results of the materials tested in strong alkaline water with $\mathrm{pH} 12.5$ (for two months).

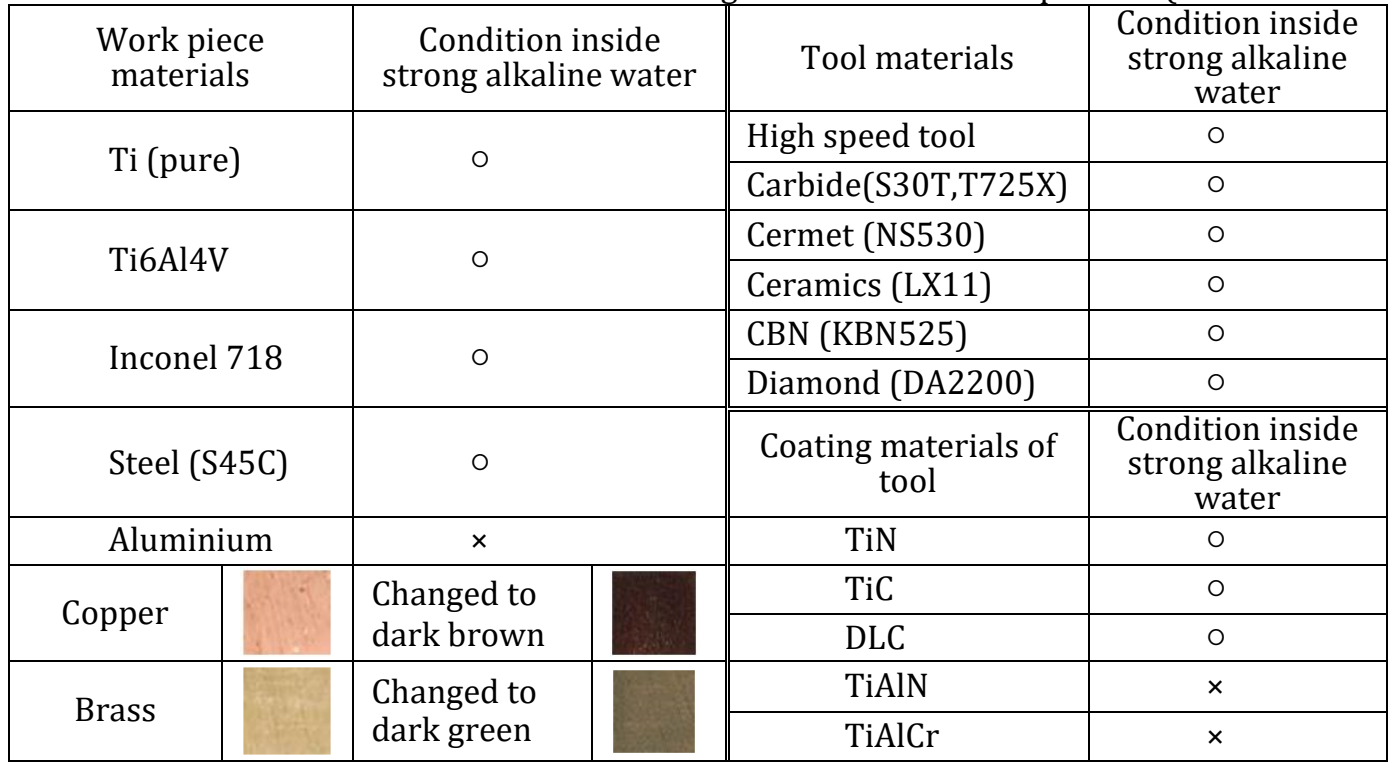

From the aforementioned facts, it was considered that it was possible to operate said materials underwater.

In the experiment, the tested materials were steel, titanium alloy, nickel alloy, copper, aluminium, brass and carbide (tool material) as shown in Table 2. These materials were put in test tubes containing water with three $\mathrm{pH}$ values, $\mathrm{pH} 7.0, \mathrm{pH} 10.0, \mathrm{pH} 12.5$ and kept in a room at a constant temperature of $20 \pm 1^{\circ} \mathrm{C}$ and a $60 \%$ moisture for two months (Table 2). The alkaline water was changed once a week to keep constant $\mathrm{pH}$ values.

The result of the experiment regarding to alkaline resistance of the materials are shown in Table 3 . The results showed that there was no corrosion on the tested materials that were kept inside strong alkaline water for two months except for aluminium. From this result, it was confirmed that the underwater cutting process for titanium alloys and nickel alloys can be applicable for a forced tool cooling effect. In the case of aluminium, it was thought that it was necessary to take appropriate precautions as it corroded in strong alkaline water. Finally, in the case of copper and brass, a change of color occurred. Due to the observed high corrosion resistance of the mentioned materials, it was concluded that strong alkaline water could be used for the forced cooling under the Double-ECO model aided by the two calculation models proposed.

\subsection{Cooling Properties of Strong Alkaline Water Mist}

The cooling properties of strong alkaline water mist were measured in this section. The experimental set-up is shown in Fig. 3. Here, the nozzle consisted of an air tube $(1 \times 7 \mathrm{~mm})$ and a tube $(7 \times 7 \mathrm{~mm})$ of strong alkaline water. A sensor for measuring heat transfer coefficient and a manufactured nozzle were set in the centre of the vessel $(556 \times 386 \times 310 \mathrm{~mm})$. The sensor for measuring heat transfer coefficient consisted of a ceramic heater $(5 \times 5 \times 1.75 \mathrm{~mm})$, two steel plates $(5 \times 5 \times 0.06 \mathrm{~mm})$ and 4 thermocouples. The ceramic 
heater was placed between two steel plates and had a power input $E(7.8 \mathrm{~W})$.

At this time, temperature on the steel plate was about $100^{\circ} \mathrm{C}$ in the air. Two thermo-couples measured temperatures $T_{\mathrm{w} 1}$ and $T_{\mathrm{w} 2}$ on the centre of each steel plate. Another two thermocouples measured temperatures $T_{\mathrm{M} 1}$ and $T_{\mathrm{M} 2}$ of the strong alkaline water mist at a $5 \mathrm{~mm}$ distance from each steel plate. Heat transfer coefficient $\alpha$ was calculated by equation (3).

$\alpha=\left(\frac{E / 2}{A\left(T_{\mathrm{w} 1}-T_{\mathrm{M} 1}\right)}+\frac{E / 2}{A\left(T_{\mathrm{w} 2}-T_{\mathrm{M} 2}\right)}\right) \times 0.5$

Where $A(5 \times 5 \mathrm{~mm})$ is the steel plate area. The heat transfer coefficient average on both steel plates was calculated.

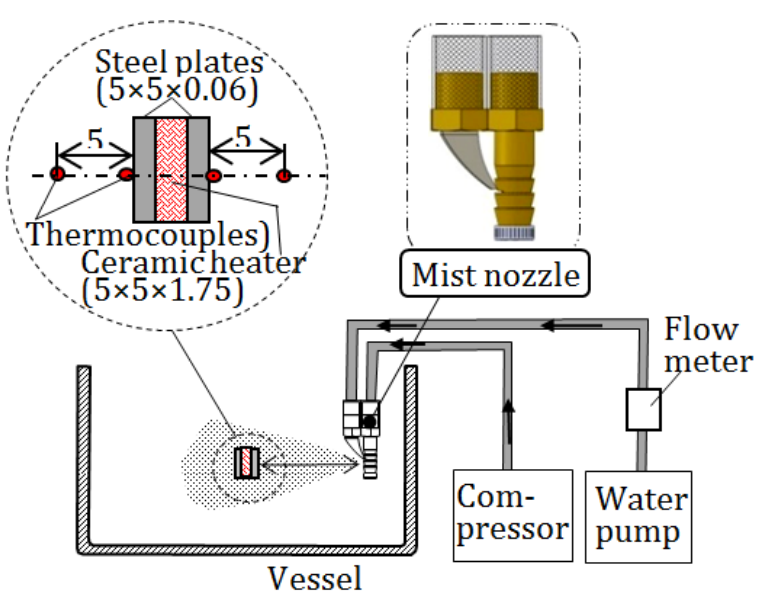

Figure 3. Experimental set-up for measuring the heat transfer coefficient of strong alkaline water mist.

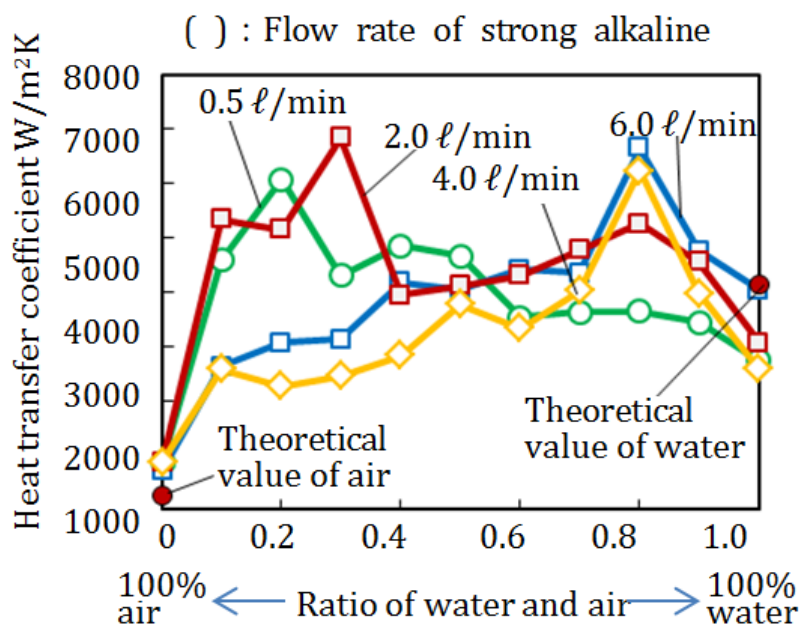

Figure 4. Relationship between the heat transfer coefficient and the ratio of air and strong alkaline water.
The relationship between the heat transfer coefficient and the mixture ratio of air and strong alkaline water is shown in Fig. 4. In this case, the length $L$ from output nozzle to measuring point was $225 \mathrm{~mm}$. The parameter considered here was the total flow rate of strong alkaline water. In this figure it can be observed that one two strong alkaline water stream variations were used; the mist condition (fine strong alkaline water) which has a very large forced cooling effect due to the heat of vaporization, and the other one is the fluid condition (fine air pockets) which has a very large heat transfer coefficient because it presents a high speed. These results clearly show that the forced cooling using strong alkaline water has a significant cooling performance. Here, the heat transfer coefficient measurements should be considered as the apparent heat transfer coefficient as the sensors surface thermal radiation might have played an error factor role. Thus, it can be said that thermal deformation during machining can be effectively cooled down by using a strong alkaline water mist. Additionally, strong alkaline water mist can be used for forced cooling as a technology inside the Double-ECO model and the two proposed calculation models due to its considerable heat transfer coefficient performance.

\subsection{Strong Alkaline Water as Cutting Liquid: Cutting Properties during Milling}

Cutting fluids or MQL (minimum quantity lubrication) are commonly used for forced cooling during machining processes [12], [13]. However, most cutting fluids pollute the environment and most MQL agents' cooling performance is inferior to other cooling alternatives. In this section, a CNC milling machine was used for experimentation to observe and evaluate the effects of using strong alkaline water mist as cutting liquid. The evaluation consisted in three parameters: tool temperature during cutting, surface roughness and the tool life parameters [14]. In this regard, the entirety of the experimental data and further explanation about it can be consulted in a parallel research [14].

First, the evaluation of tool temperature during cutting was done using the experimental set-up shown in Fig. 5. Here, the cutting area was surrounded by a strong alkaline water and microbubbles mist and two thermocouples placed near the cutting tool tip. The cutting conditions described a middle milling pattern as shown in Table 3. On the other hand, the mist had a $113.3 \ell / \mathrm{min}$ amount of air and the total strong alkaline 
water flow rate was $0.82 \ell / \mathrm{min}$ and the $L \mathrm{~mm}$ from output nozzle to measuring point was $50 \mathrm{~mm}$.

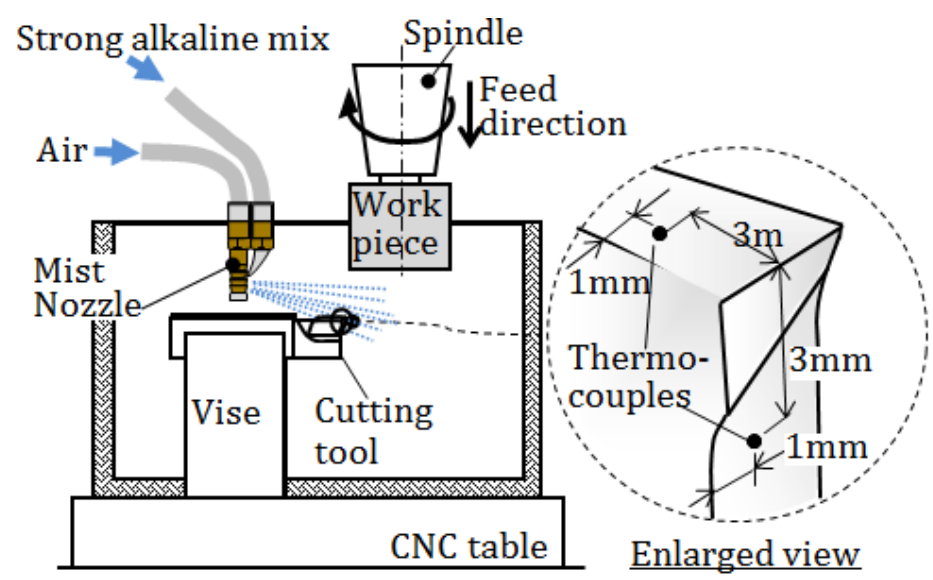

Figure 5. Experimental setup for measurement of tool temperature.

Table 3. Cutting conditions for tool temperature measurement.

\begin{tabular}{|c|c|c|}
\hline \multicolumn{3}{|c|}{ Cutting conditions } \\
\hline $\begin{array}{c}\text { Cutting speed } \\
80 \mathrm{~m} / \mathrm{min}\end{array}$ & $\begin{array}{c}\text { Feed speed } \\
0.25 \mathrm{~mm} / \mathrm{rev}\end{array}$ & $\begin{array}{c}\text { Depth of cut } \\
0.4 \mathrm{~mm}\end{array}$ \\
\hline \multicolumn{3}{|c|}{ Work piece } \\
\hline \multicolumn{3}{|c|}{ Material : S50C } \\
\hline \multicolumn{2}{|c|}{ Tool (Bite) } \\
\hline Rake angle: $5^{\circ}$ & Coated carbide \\
\hline
\end{tabular}

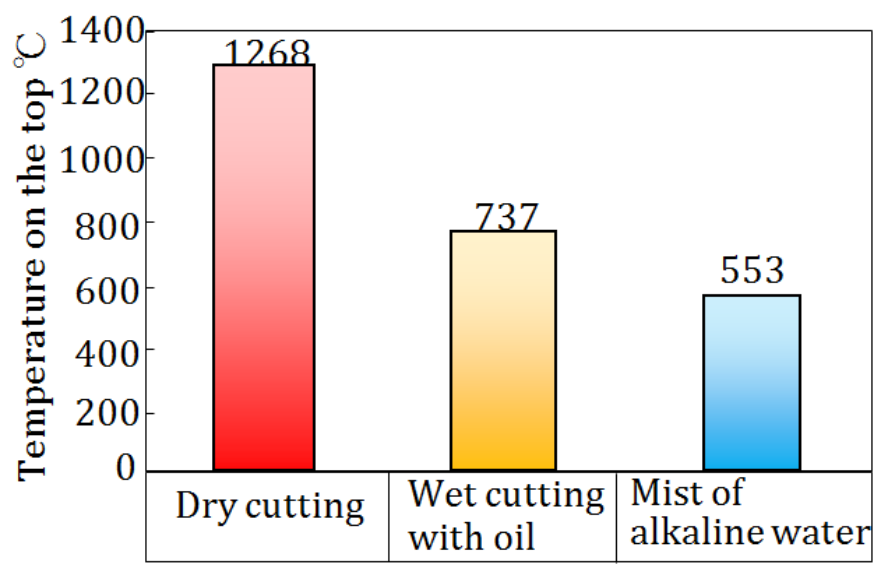

Figure 6. Experimental results for temperature on the top.

In Fig. 5, as conventional milling process would make the use of thermocouples difficult, the workpiece was fixed to the spindle and the tool was fixed to the CNC machine table vise. The tool tip temperature was estimated using the finite element method (FEM). The experimental data obtained through the thermocouple measurements the tool tip allowed a calculation of the tool heat transfer coefficient and the amount of generated heat. As a result, it was possible to obtain an approximation of the tool tip temperature that was considered the representative temperature [11].

Temperatures on the top of the tool are summarized in Fig. 6. Dry cutting and wet cutting with oil are also shown for reference. Material of the used tool was coated carbide and its optimum temperature for cutting is about $800^{\circ} \mathrm{C}$. Temperature on the top of the tool using mist of strong alkaline water was $44 \%$ that of dry cutting and $75 \%$ that of oil wet cutting. Thus, strong alkaline water mist was deemed as an effective method for tool cooling.

Second, the evaluation of tool life during cutting was done using a conventional milling set-up shown in Fig. 7 (Dry cutting and oil wet cutting were also performed for reference). Here, the objective cutting area was surrounded with a strong alkaline water mist. The cutting conditions described a middle milling pattern as shown in Table 4. On the other hand, the mist had a $113.3 \ell / \mathrm{min}$ amount of air and the total strong alkaline water flow rate was $0.82 \ell / \mathrm{min}$ and the $L \mathrm{~mm}$ from output nozzle to measuring point was $50 \mathrm{~mm}$. An End-mill with 2 throw away inserts was used as milling tool due to the simplicity to measure limit of tool life that it presents. The results of the tool life tests are shown in Fig. 8. Here, it was observed that that the tool life of the tool using mist of strong alkaline water was 2.5 times of that of dry cutting and 1.4 times that of oil wet cutting.

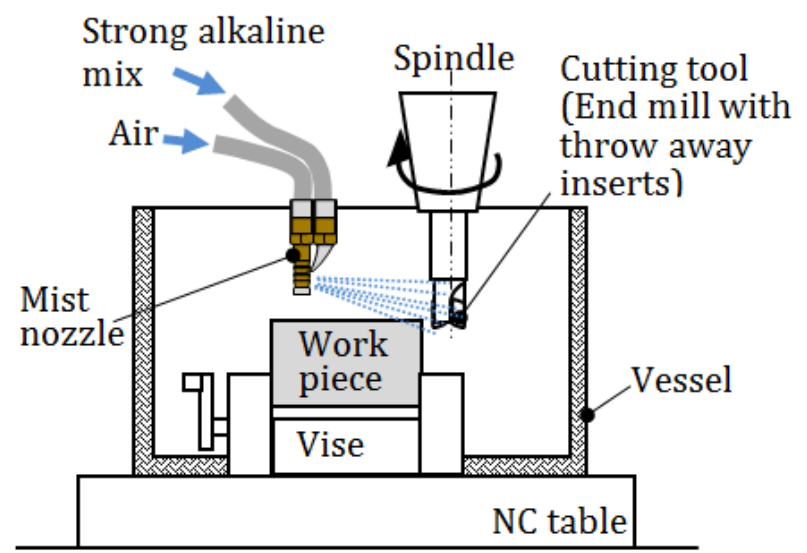

Figure 7. Experimental set-up for measurement of tool life and surface roughness. 
Table 4. Cutting conditions for tool life.

\begin{tabular}{|l|l|l|l|}
\hline \multicolumn{4}{|c|}{ Cutting conditions } \\
\hline $\begin{array}{l}\text { Cutting } \\
\text { speed } \\
100 \\
\mathrm{~m} / \mathrm{min}\end{array}$ & $\begin{array}{l}\text { Feed/tooth } \\
\mathrm{mm} / \text { tooth }\end{array}$ & Width of & Depth of \\
\hline \multicolumn{3}{|c|}{ Work piece } \\
\hline \multicolumn{3}{|c|}{ Material : S50C } \\
\hline \multicolumn{3}{|c|}{ Tool (End mill with 2 throw away tips) } \\
\hline \multicolumn{3}{|c|}{ Rake angle: $5^{\circ}$} & Coated carbide \\
\hline
\end{tabular}

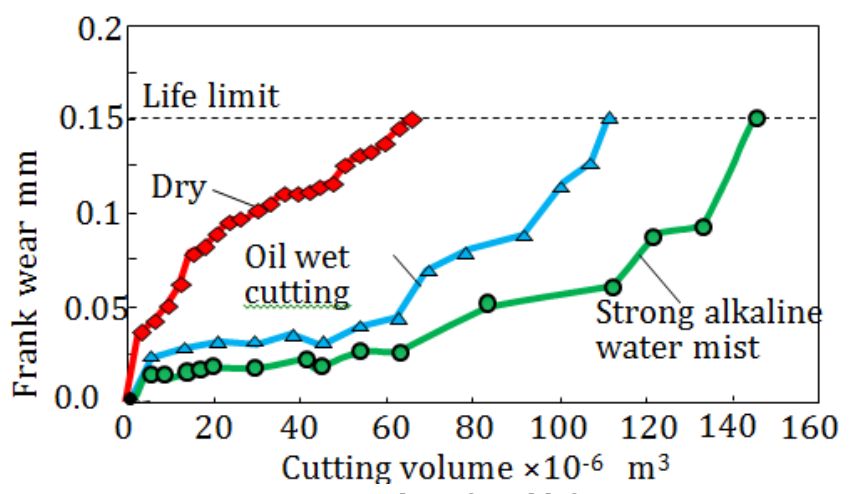

Figure 8. Results of tool life test.

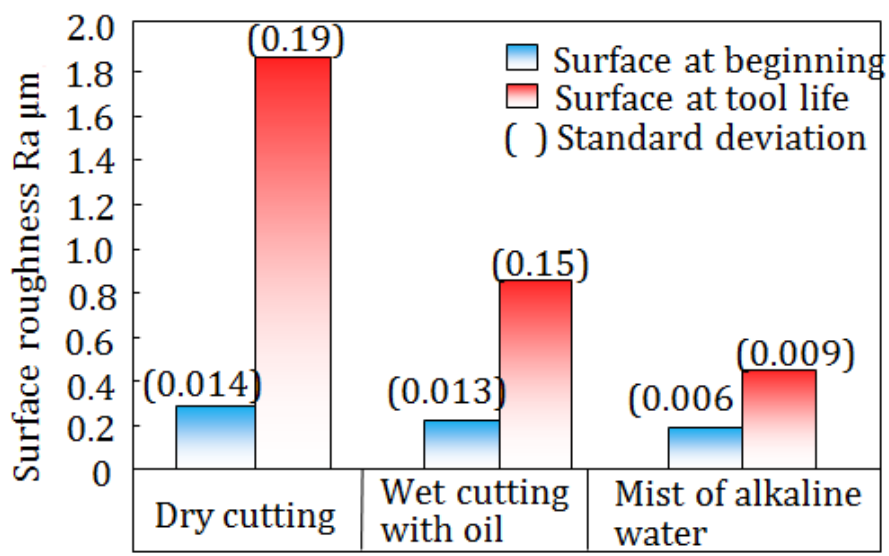

Figure 9. Results of surface roughness.

Hence, it is thought that a mist of strong alkaline water was an effective method for extending the tool life during machining. Similarly, in the case of the cutting using mist of strong alkaline water, defects were not observable in the microscope. Here, surface roughness test results shown in Fig. 9 demonstrate that strong alkaline water mist achieved a better surface finish when compare to existing cutting methods.

\subsection{Evaluation and Considerations Regarding Machining using Strong Alkaline Water Mist using the Proposed Models}

First, the environmental impact of the proposed cooling technology was assessed based on a comparison of the amount of exhaust $\mathrm{CO}_{2}$ of the proposed and conventional cooling as shown in Fig. 10. In the case of the conventional method, it was considered that the power used by the coolant pump on the milling machine during conventional wet cutting was $1.2 \mathrm{~kW}$ and a working year being composed of 250 days and one 8hours shift per day. Furthermore, the amount of $\mathrm{CO}_{2}$ emissions due to electricity consumption, $E C_{E}$, was calculated by using equation (1). $W_{E}$ was the amount of used electricity (kWh) used in the coolant pump and 0.468 the conversion value for $\mathrm{kg}-\mathrm{CO}_{2} / \mathrm{kWh}$.

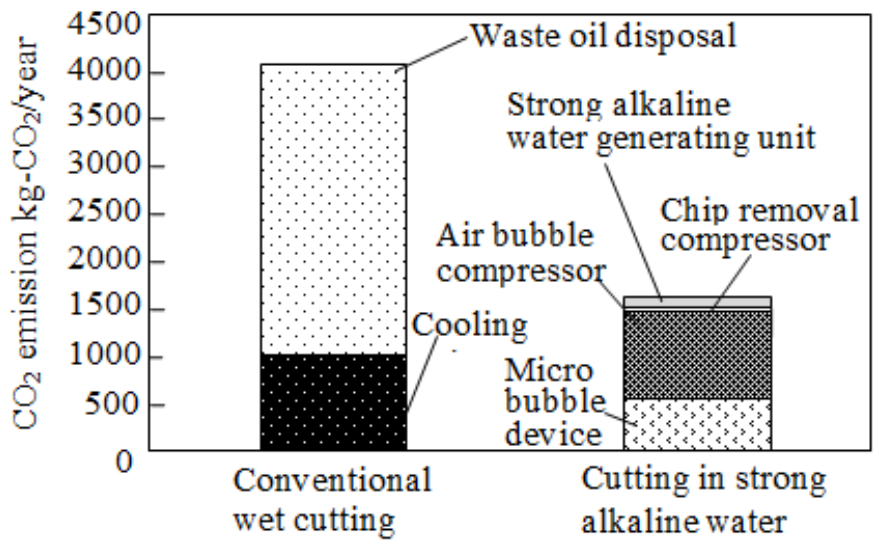

Figure 10. Comparison of $\mathrm{CO}_{2}$ emissions.

Table 5. Cooling expenses general overview.

\begin{tabular}{|c|c|c|}
\hline Category & Conventional & Proposed \\
\hline Initial cost & $\begin{array}{c}\text { Alkaline water } \\
\text { devices } \circ\end{array}$ & Cooling device $\circ$ \\
\hline Running cost & Electricity $\times$ & $\begin{array}{c}\text { Electricity } \times \\
\text { Oil supply } \times\end{array}$ \\
\hline Maintenance & Few times $\bigcirc$ & Constant $\times$ \\
\hline Note: Symbols $=(0:$ Cheap, $\circ:$ Moderate, $\times$ : Expensive \\
\hline
\end{tabular}

Here, the calculated amount of $\mathrm{CO}_{2}$ emissions from the coolant pump was $1123.2 \mathrm{~kg}-\mathrm{CO}_{2}$. Subsequently, the amount of $\mathrm{CO}_{2}$ emissions due to oil consumption, $E C_{o}$, was calculated by using equation (2). In this case, the amount of oil was assumed to be $340 \ell$ and disposal times to be 2 times a year. However, milling machines require a monthly oil fill-up which was assumed to be $30 \ell$ a month (30 $\ell \times 12$ months $=360$ $\ell)$. Hence, the total amount of disposed oil was $1040 \ell$. Where, the emitted heat energy EHE was $40.2 \mathrm{GJ} / \mathrm{k} \ell$ 
and the amount of carbon emission $C E$ was $19.22 \mathrm{t}-\mathrm{C}$ / TJ. Here, the calculated amount of $\mathrm{CO}_{2}$ emissions from oil consumption was $2946.3 \mathrm{~kg}-\mathrm{CO}_{2}$. Therefore, the total amount of $\mathrm{CO}_{2}$ emitted was $4069.5 \mathrm{~kg}-\mathrm{CO}_{2}$.

In the case of the strong alkaline water method, it was considered that the power used by the air compressor, microbubble device and chip removal pump on the proposed cutting were $0.95 \mathrm{~kW}, 0.56 \mathrm{~kW}$, $0.0132 \mathrm{~kW}$ respectively. Here, the usage time was considered to be a working year being composed of 250 days and one 8-hours shift per day. Additionally, the strong alkaline water generating unit had a power of $0.75 \mathrm{~kW}$ and a $25 \mathrm{~h}$ usage time per year. Furthermore, the amount of $\mathrm{CO}_{2}$ emissions due to electricity consumption, $E C_{E}$, was calculated by using equation (1). Here, the calculated amount of $\mathrm{CO}_{2}$ emissions from electricity consumption was $1434.6 \mathrm{~kg}-\mathrm{CO}_{2}$ (64.7\% reduction in a year). Here, as no oil consumption was generated the calculations from equation (2) were omitted. Thus, it can be considered that this method is not only effective in cooling the machine tool but also capable of reducing the impact to the environment. Finally, a comparison between the expenses involved in the proposed cooling and the conventional cooling during machining is shown in Table 5. It can be noted that the proposal is more affordable, given that the initial costs would be considerably less because of the low market price of alkaline water. Thus, the proposed system goal of simultaneously reaching a "highly costeffective" and "environmentally-friendly" technology was achieved.

\section{Conclusions}

1. The Double-ECO Model was used as this model reconciles "Economy" and "Ecology" by exploring technological trends and setting the same degree of priority to these categories and mechanical performance during the technology development process. Here, calculation models for checking environmental-friendliness were also effective in creating an evaluation reference.

2. The application of the Double-ECO Model into real production engineering problems and technology was proposed and presented through the "Forced cooling using mist of strong alkaline water" researches that demonstrate its potential.

3. It was concluded from the experimental results of the proposed mist technology, that improvements in the environmental pollution, mechanical properties and cost parameters were achieved through the proposed research.

\section{References}

[1] I. Tanabe and M. T. Hong "Cutting with an environment-friendly cooling method using water evaporation," Transactions of Japan Society of Mechanical Engineers, vol. 67, no. 664, Series C, pp. 4011-4016, 2001. (In Japanese)

[2] e-Gov Japan, Ordinance related to calculation for carbon dioxide equivalent greenhouse gas emissions with their business activities of specified emitters, Article 2, 2013. [Online]. Available: http://law.egov.go.jp/htmldata/H18/H18F15002002003.html

[3] I. Tanabe, H. M. Truong, K. Yoshii "Turning with environment-friendly cooling method using water evaporation," Transactions of the Japan Society of Mechanical Engineer, series C, vol. 66, no. 643, pp. 1026-1030, 2000. (in Japanese)

[4] I. Tanabe and H. M. Truong "Cutting with an environment-friendly cooling method using water evaporation," Trans. of Japan Society of Mechanical Engineers, vol. 67, no. 664, series C, pp. 4011-4016, 2001. (In Japanese)

[5] I. Tanabe, K. Yamanaka, J. Mizutani and Y. Yamada "A new design of lathe structure for reducing thermal deformation (Design of zero-center on three directions, self-compulsory cooling and design of thermal synchronism)," Transactions of Japan Society of Mechanical Engineers, series C, vol. 65, no. 639, pp. 4508-4513, 1999. (In Japanese)

[6] I. Tanabe, H. S. Ye, T. Iyama and Y. Abe "Control of tool temperature using neural network for machining work-piece with low thermal conductivity," Transactions of Japan Society of Mechanical Engineers, series C, vol. 77, no. 776, pp. 1556-1564, 2011. (In Japanese)

[7] I. Tanabe, "Double-ECO model technologies for and environmentally-friendly manufacturing," Procedia CIRP: 23rd CIRP Conference on Life Cycle Engineering, vol. 48, 495-501, 2016.

[8] M. Inkbeiner, A. Inaba, et al., "The New International Standards for Life Cycle Assessment: ISO 14040 and ISO 14044," The International Journal of Life Cycle Assessment, vol. 11, pp. 80-85, 2006.

[9] Enviroment agency, Law (enforce No. 3) for Global Warming Countermeasures in Japan-(Exhaust coefficient list), 2006. 
[10] P. Saling, A. Kicherer, B. Dittrich-Krämer, et al., "Eco-efficiency Analysis by BASF: The Method," The International Journal of Life Cycle Assessment, vol. 7, no. 4, pp. 203-218, 2002.

[11] S. Shiddaira, Material science for corrosion and corrosion resistance. AGNE technological center, pp. 30-32, 255-257, 287-288, 1995. (In Japanese)

[12] S. Shintani, Hand book for cutting fluid. Kogyo Chosakai Publishing Co., Ltd., 2004, pp. 33-48. (In Japanese)

[13] M. Okada, A. Hosokawa, N. Asakawa, Y. Fujita and T. Ueda "Influence of minimum quantity lubrication on tool temperature in end milling of difficult-to-cut materials having low thermal conductivity," Transactions of Japan Society of Mechanical Engineer, series C, vol. 78, no. 792, pp. 3093-3103, 2012. (In Japanese)

[14] I. Tanabe "Development of forced cooling using mist of strong alkaline water for restraining thermal deformation on a machine tool," MM-science Journal, pp. 521-526, 2014 